\title{
Dominant tree species identity effects on soil fungi are context dependent
}

\author{
Shi $\mathrm{LL}^{1,2 \#}$, Wen $\mathrm{Y}^{3 \#}$,Yang $\mathrm{ZJ}^{4}$, Zang $\mathrm{HD}^{1}$, Gui $\mathbf{H}^{1,2}$, Zou $\mathrm{XM}^{5}$ and Mortimer $\mathrm{P}^{1,2^{*}}$ \\ ${ }^{1}$ Department of Agricultural Soil Science, University of Goettingen, 37077, Goettingen, Germany \\ ${ }^{2}$ Key Laboratory for Plant Diversity and Biogeography of East Asia, Kunming Institute of Botany, Chinese Academy of \\ Sciences, Kunming, China \\ ${ }^{3}$ School of Environment, Natural Resources and Geography, Bangor University, Gwynedd LL57 2UW, UK \\ ${ }^{4}$ Fujian Provincial Key Laboratory of Subtropical Resources and Environment, Fuzhou 350007, China \\ ${ }^{5}$ Institute for Tropical Ecosystem Studies, University of Puerto Rico, P.O. Box 70377, San Juan, PR 00931-8377, USA
}

Shi LL, Wen Y, Yang ZJ, Zang HD, Gui H, Zou XM, Mortimer P 2018 - Dominant tree species identity effects on soil fungi are context dependent. Mycosphere 9(4), 790-802, Doi 10.5943/mycosphere/9/4/7

\begin{abstract}
Fungal Fungi diversity and community composition are mainly depending on soil and vegetation factors. However, the effects of these drivers on different fungal taxonomy and functional guilds remain largely unexplored, especially in subtropical forest ecosystems. The soil was collected from five dominate tree species forests: Castanopsis carlesii, Castanopsis fabri, Cinnamomum chekiangense, Schima superb, and Cunninghamia lanceolata in Wanmulin National Nature Reserve of South-eastern China. Fungal communities in rhizosphere and bulk soil were assessed employing ITS rDNA illumina sequencing. Ascomycota dominated the fungal community and most of them belong to Saprotrophic fungal group. On the genus level, Cladophialophora, Spirosphaera, and Podospora were dominate in soils of Castanopsis carlesii, Castanopsis fabri, and Cinnamomum chekiangense (> 50\% of the OTUs), respectively. Analysis of similarity showed that the Ascomycota and Saprotrophic fungi rather than total fungal community were significantly different among the soils with different dominant tree species. Furthermore, Ascomycota community were affected by soil $\mathrm{C}, \mathrm{C} / \mathrm{N}$, and total K, while Saprotrophic fungi were explained by changes in tree richness, diameter at breast height and soil available P. In conclusion, our analyses revealed that the effects of dominant tree species on soil fungi are largely depend on different taxonomic and functional groups levels.
\end{abstract}

Key words - Ascomycota - Illumina sequencing - Saprotrophic - Subtropical forest

\section{Introduction}

The interaction between aboveground plant biomass and belowground microbial communities drives the stability and function of terrestrial ecosystems (Bardgett \& van der Putten 2014). Fungi are important soil microorganisms, forming Symbiotic associations with plant, and mediate the nutrient and energy flux between plants and soil in many ecosystems. In forest ecosystems, trees play a prominent role in aboveground and belowground interaction (Wardle et al. 2004, Pineda et al. 2015. Trees provide photosynthetic carbon (C) to support the fungal maintenance and growth, and mediate soil fungal community (Tedersoo et al. 2014). In return, fungi play vital roles in the 
decomposition of organic matter, nutrient cycling, and plant nutrient availability, and thus influence tree diversity, composition and functional traits (Wagg et al. 2014). However, little is known about the effects of dominate tree species on soil fungal communities in subtropical forest.

Dominant tree species produce most of the litter in the forest which accumulates on soil surface. This organic layer providing a habitat for soil fungi, as well as acting as a source of $\mathrm{C}$ and nutrient (Holste \& Kobe 2017). Different tree species vary in the litter quantity and quality, and consequently influence the soil fungi community for utilizing these substrates (Bödeker et al. 2016). C to nitrogen (N) ratio, lignin and cellulose concentration, as well as $\mathrm{pH}$ are important litter characteristics affecting soil fungi (Purahong et al. 2016). Soil fungal community included different functional groups and habitat in different area in the forests. Saprotrophic fungi commonly dominate in bulk soil while symbiotic fungi dominate in rhizosphere area. Tree species specify effects on symbiotic fungi have been reported in several studies (Schimann et al. 2017). However, to what condition the tree species effects on Saprotrophic fungi in the bulk soil still need to be discussed (Tedersoo et al. 2016). Plant trenching experiment found that symbiotic mycorrhizal fungi deletion resulted in increase the diversity of Saprotrophic fungi (Lindahl et al. 2010). Therefore, individual tree might not only affect soil fungi in the sphere but also a broad range of Saprotrophic soil fungi in bulk soil. Dominating tree species have the highest coverage in the forest community, which can expect to be strong indicator in shaping the Saprotrophic soil fungi in the forestry ecosystem (Hiiesalu et al. 2017). Besides dominate tree species, tree physiology and soil properties are also important factors that affecting Saprotrophic soil fungi. Tree age and growth stage, for example, can affect the soil fungi by changes of litter quantity and quality, root exudates and root-symbioses diversity and function (mycorrhizal fungi especially) (Ortega-Martínez et al. 2011, Clemmensen et al. 2015).

Moreover, the soil fungal community is also affected by soil physical and chemical characteristics, including soil $\mathrm{pH}$, temperature, moisture, available $\mathrm{C}$ and $\mathrm{N}$, all of which can be correlated with geographical location (Abarenkov et al. 2010, Sterkenburg et al. 2015). Pellissier (Pellissier et al. 2014) has investigated soil alpha and beta diversity and composition across a landscape grassland soils, suggested that environmental factors are directly affecting soil fungal and mediated by plant community. Our previous large-scale fungi biogeography studies in forest ecosystem have demonstrated that the distribution of soil total fungal diversity is shaped by interactions between soil environment, climate and also plant community (Shi et al. 2014). However, those studies have been performed across landscape area, of that complex environmental factors have burred the correlation between dominant tree species and the Saprotrophic soil fungi (Tedersoo et al. 2016).

The aim of the current study is to investigate the extent to which the dominant tree species shapes soil fungal community composition in subtropical mountain forests in the bulk soil. To address this, we choose a sampling site in Wanmulin Nature Reserve, Jian'ou, Fujian, China, where growing an old-growth mixed forest with various dominant tree species but with similar parent soil material (Yang et al. 2007). We hypothesis that (1) soil fungi community composition varied with dominant tree species in forests; (2) each dominant tree species have unique soil fungi indicator groups; (3) soil fungal community are depending on dominant tree species rather than other environmental factors.

\section{Materials \& Methods}

\section{Study sites}

The site is located in Wanmulin Nature Reserve in Jian'ou, Fujian Province, China ( $27^{\circ} 03^{\prime} \mathrm{N}$, $\left.118^{\circ} 09^{\prime} \mathrm{E}\right)$. The Wanmulin Nature Reserve borders the Jiufeng Mountains on the southeast and the Wuyi Mountains on the northwest. The region has a middle subtropical monsoonal climate, with a mean annual air temperature of $18.7^{\circ} \mathrm{C}$. The mean annual precipitation is $1670 \mathrm{~mm}$ and mainly occurring from March to August. Mean annual evapotranspiration is $1466 \mathrm{~mm}$. The growing season 
equals the annual frost-free period of around 277 days. The parent material of the soil is granite and the soils are characterized as humid Planosols according to material (Yang et al. 2007).

Five forests were selected in the nature reserve, with the following dominant tree species: Castanopsis carlesii (Castanopsis_c), Castanopsis fabri (Castanopsis_f), Cinnamomum chekiangense (Cinnamomum), Cunninghamia lanceolata (Cunninghamia) and Schima superb (Schima). The geographic location, soil characteristics and plant phenology of these forests have been previously documented material (Yang et al. 2007). In each forest, three $20 \mathrm{~m} \times 20 \mathrm{~m}$ plots were set up as replicates, each consisting of five sampling points ( $>2 \mathrm{~m}$ from nearby tree). To avoid the effects of nearby tree, we chose sampling points at least $1 \mathrm{~m}$ from the tree root. The soils from each plot was mixed and make one composite sample. The typical distance between replication of the same species was 1-4 km, and other species were usually located less than $1 \mathrm{~km}$ apart. In each forest type, a study area was chosen at least $25 \mathrm{~m}$ from the forest edge. The age of each site was considered to be the time since the last major disturbance, ranged from 20 to 150 years material (Yang et al. 2007). Cunninghamia is the youngest forest, with development for less than 20 years, while the other four forests are all older than 100 years.

\section{Sample collection and DNA extraction}

Samples were collected in late October 2011, immediately after litter fall. Fresh litter and twigs were removed from the sub-plots and for each site soil cores were taken to the depth of $10 \mathrm{~cm}$ by gently pounding metal rings into the ground. After leaves and roots were removed, the samples were transported to the laboratory in sterile plastic bags on ice and stored at $-20{ }^{\circ} \mathrm{C}$. DNA extractions were performed on $0.5 \mathrm{~g}$ of soil samples using the Ultra Clean ${ }^{\mathrm{TM}}$ Mega Prep Soil DNA kit (Mo Bio Labs, Solana Beach, CA, USA) following the manufacturer's protocol. The purified DNA was detected by agarose gel electrophoresis. The purity and usefulness of the DNA samples were ultimately determined by successful PCR amplifications.

\section{DNA amplicon and Illumina sequencing of fungal communities}

We amplified the ITS1 region using the newly developed primerITS1FI2, 50GAACCWGCGGARGGATCA-30 and ITS2 (Schmidt et al. 2013). Amplifications were carried out in a total volume of $20 \mathrm{ml}$ using $50 \mathrm{ng}$ of DNA, $4 \mathrm{ml}$ of HOT MOLPolBlend Master Mix (Molegene, Germany), and $0.5 \mathrm{mM}$ of each of forward and reverse primers. PCR conditions were $15 \mathrm{~min}$ at $95^{\circ} \mathrm{C}$, followed by 35 cycles of $30 \mathrm{~s}$ at $95^{\circ} \mathrm{C}, 30 \mathrm{~s}$ at either $52^{\circ} \mathrm{C}, 55^{\circ} \mathrm{C}$ or $58^{\circ} \mathrm{C}$, and $30 \mathrm{~s}$ at $72^{\circ} \mathrm{C}$. PCR with $52^{\circ} \mathrm{C}$ annealing temperature was repeated three times. Final elongation was done at $72^{\circ} \mathrm{C}$ for $5 \mathrm{~min}$. Amplicons from the five parallel PCR runs $\left(3 \times 52^{\circ} \mathrm{C}, 1 \times 55^{\circ} \mathrm{C}, 1 \times 58^{\circ} \mathrm{C}\right)$ were individually labeled to estimate the effect of repeated PCRs and annealing temperatures on richness recovery. Purification was done with AgencourtAMPure XP SPRI magnetic beads. PCR products were normalized and pooled. We normalized PCR products after quantifying them with a Qubit 2.0 Fluorometer (Invitrogen), and the Qubitds DNA HS Assay Kit (Invitrogen). Paired-end sequencing ( $2 \times 150$ bp) was carried out on an Illumina MiSeq sequencer at the Research and Testing Laboratory, U.S.A.

\section{Bioinformatics analysis}

The pyrosequencing data were processed using the pipeline SEED with the proposed procedures of standardized data analysis (Henrik Nilsson et al. 2011, Větrovský \& Baldrian 2013). Pyrosequencing resulted in a median length of 410 bases. By use of Denoiser 0.851 (Reeder \& Knight 2010) these sequences were re-assigned to samples based on the barcodes, and quality trimmed to exclude short and low-quality sequences. The resulting sequences were subjected to removal of chimeric sequences by use of the UCHIME software (Edgar et al. 2011). Sequences were shortened to 150 base pairs, and any sequences shorter than 150 base pairs were removed. These sequences are then clustered into OTUs using the UPARSE algorithm base on at $98.0 \%$ sequence similarity. Compared with the routinely used $97 \%$, this threshold is a better proxy at species level in several groups of fungi (Kõljalg et al. 2013). These singletons were removed from 
further analyses, because these comprise a high proportion of technical artefacts (Tedersoo et al. 2010). The longest sequence of each clusters was selected as a representative for BLASTn sequence similarity against the UNITE databases. The output is then analyzed using an internally developed python program that assigns taxonomic information (species, genus, order and family) to each sequence and then computes and writes the final analysis files. Furthermore, we assigned each fungal genus to functional categories, including Saprotrophic, Pathogenic and Symbiotic fungi using FUNGLUID database (Nguyen et al. 2016). The sequence data were deposited in the NCBI public database (https://www.ncbi.nlm.nih.gov/, sequences numbers SAMN07727536 to 7727550).

\section{Statistical analyses}

The alpha diversity index, species richness index were used as diversity estimates. The same dataset was also used to calculate the Bray Curtis Indices as a measure of community similarity and to explore the effects of tree species on the diversity of fungi. Because the majority of taxa were represented by a very small number of reads and because such read counts were demonstrated not to be technically reproducible in independent Illumina sequencing runs, only taxa with higher relative abundances (1\% in 3 samples) were tested for variations in abundance (Quail et al. 2008). These indices were calculated using the function' diversity' of the 'vegan' package implemented in the software R. Multiple regression analysis was used to examine the correlations between fungal diversity (alpha diversity) and each variable category (i.e., soil physical and chemical parameters, plant diversity, and spatial variables) using 'Im' of the 'vegan' package.

For data generated using Illumina sequencing, a Bray-Curtis similarity index was calculated overall community similarities were displayed using non-metric multidimensional scaling (NMDS) by function 'metaMDS' in the 'vegan' package in R (Quail et al. 2008). An analysis of the correlation between the environmental variables and community composition was also conducted using function "envfit" in the vegan package in R. P values are based on 999 permutations using MRPP analysis. We then assessed the effect of site elevation on fungal assemblage structure by analyzing the average Bray-Curtis dissimilarity index in permutational multivariate analyses of variance. These analyses were carried out with the Adonis function of the $\mathrm{R}$ vegan. To select the best model for environmental variables, we use 'step' of the 'vegan' package implemented in the software R to calculate the AIC value. The lower AIC value presents the best model and variables (Arnold 2010).

\section{Results}

\section{Fungal communities in forest soil}

In total, 310,104 raw sequences were obtained from the Illumina sequencing. Of which 203,126 were retained for further analysis after quality filtering. An average of 13,541 and minimum of 3,000 sequences was obtained per sample. All of these sequences were clustered into 856 OTUs at a 97\% similarity threshold. Fungal diversity was calculated using alpha diversity index based on OTUs composition. Among the five trees, alpha diversity was the highest in Cunninghamia soil (28), followed by Cinnamomum and Schima (14 and 15), and the lowest in Castanopsis_c and Castanopsis_f soils (5 and 6) (Fig. 1).

The soil (bulk soil) fungal communities was dominated by Ascomycota (76\% at average) and Basidiomycota (20\% at average), after excluding the unclassified OTUs (Fig. 2a). Ascomycota was especially dominated in Castanopsis_f, where it took up almost $90 \%$ of the community composition. Schima, Cinnamomum and Cunninghamia showed similar abundances of Ascomycota and Basidiomycota (70\% for Ascomycota and 20\% for Basidiomycota at average) (Fig. 2a). In addition, Chytridiomycota and Zygomycota took up less than $5 \%$ of the fungal communities in all trees (Fig. 2a). Furthermore, three tree soils present pique tree-species-specific dominating fungal genus: Cladophialophora, Spirosphaera, and Podospora were dominate in Castanopsis_c, Castanopsis_f, and Cinnamomum ( $>50 \%$ of the OTUs), respectively (Fig. 2b). On the species 
levels, Venn indicated uncultured Mortierella was the unique fungi commonly presented in all five trees.

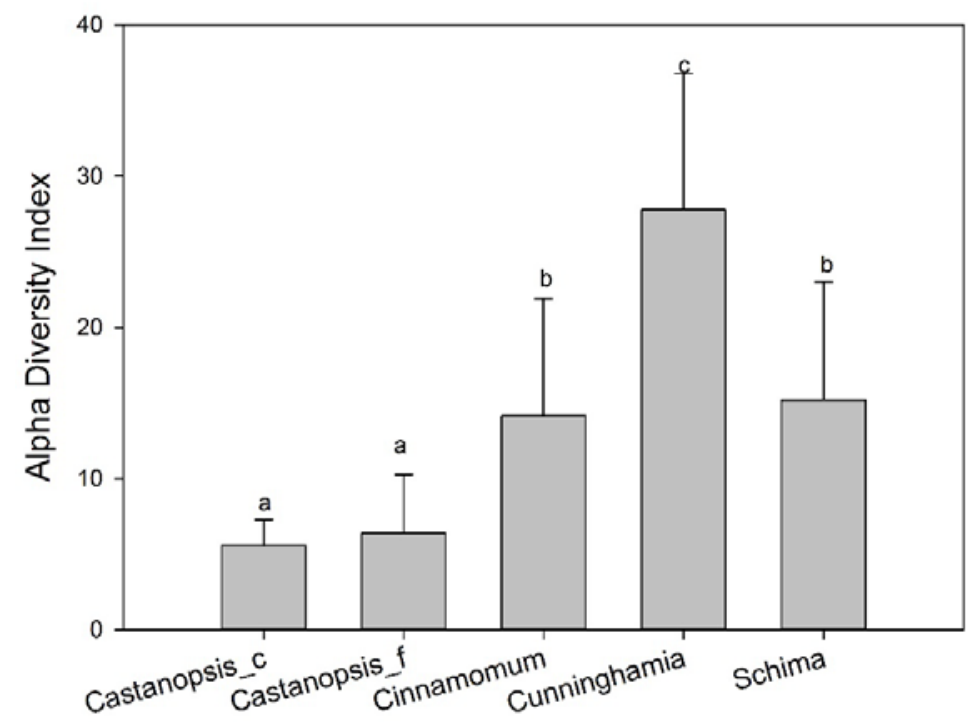

Figure 1 - Influence of dominant tree species on the fungal diversity (mean \pm se, $n=3$ ). The different letters above each column represent significant differences at the $P<0.05$ levels.
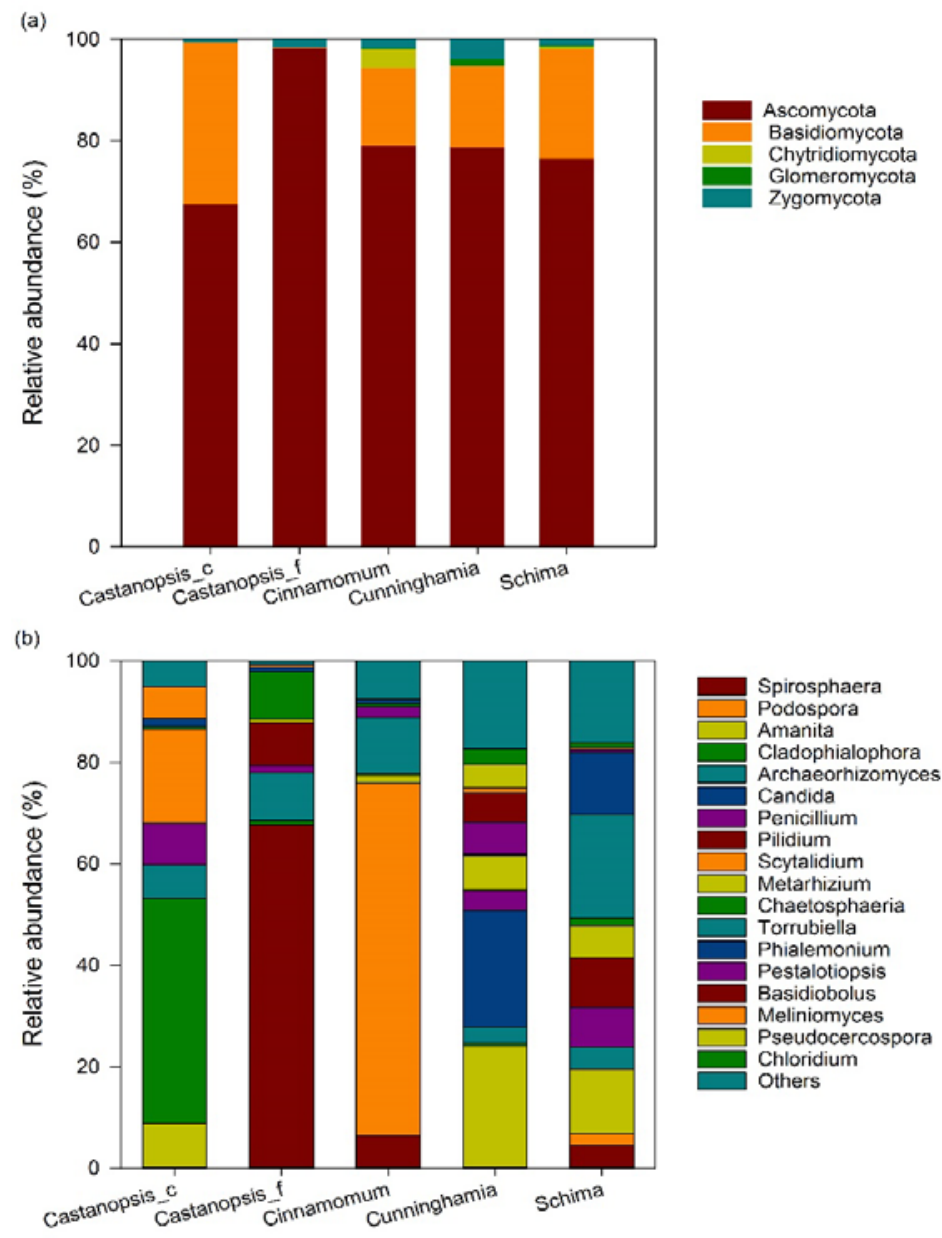

Figure 2 - Relative abundance of major soil fungal families (a) and genus composition (b) from the five dominated tree species. y axis is group percentage of the total number of OTUs per sample, after rarefaction to correct for uneven sampling effort. 
When the observed fungal taxa were divided into functional groups, Saprotrophs, Symbiotic mutualists (ectomycorrhizal fungi and arbuscular mycorrhizal fungi) and Plant pathogens comprised $47.5 \%, 17.7 \%$ and $3.5 \%$ of fungal community composition, respectively (Fig. 3). Saprotrophs has the highest relative abundance in Castanopsis_c, lower in Cunninghamia soils, and lowest in Schima and Castanopsis_f soils. Symbiotic fungi represented the highest abundances in Cunninghamia soil (with EcM fungi) and lowest in Castanopsis_f soil. Plant pathogen was higher in Cunninghamia and Schima soils than other trees. There was abundance of fungal species in Cinnamomum soil clustered as functional uncertain (Fig. 3).

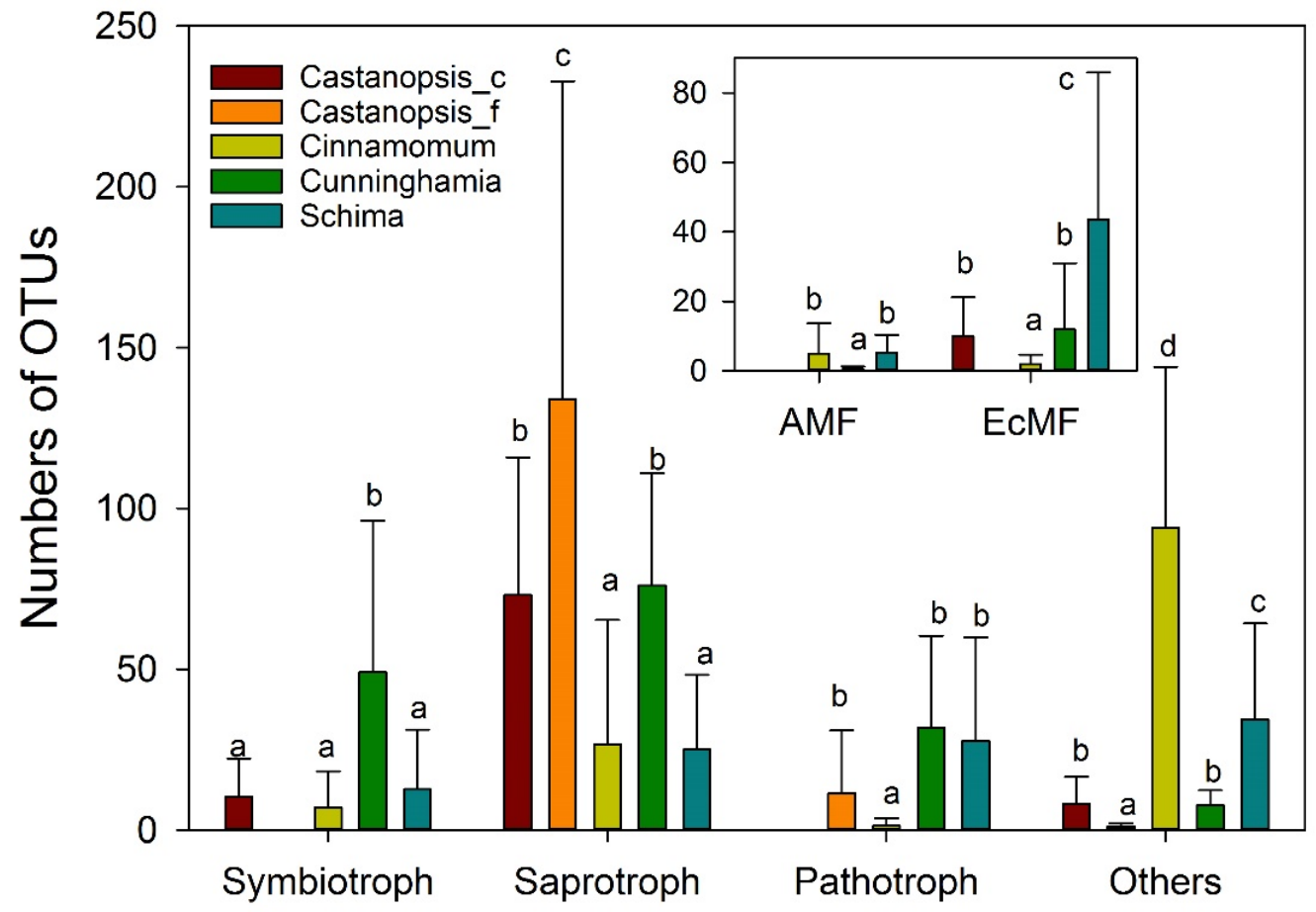

Figure 3 - Relative abundance of major soil fungal functional group from the five dominated tree species. y axis is number of OTUs per sample, after rarefaction to correct for uneven sampling effort.

\section{Effect of tree species on soil fungi}

Dominate tree species shows significant effect on soil fungal diversity on the OTU-level, which explain $47 \%$ of the variations among five tree species. Furthermore, general linear models were applied to explore the effects of environmental variables on soil fungal diversity. Soil fungal diversity was positively correlative with tree diversity $(P=0.011)$, soil $\mathrm{C} / \mathrm{N}(P=0.025)$ and soil available $\mathrm{N}(P=0.032)$ (Table 1$)$. By compare AIC values, the best model to explain the fungal diversity trend were the one with combined effects of soil $\mathrm{C} / \mathrm{N}$ and tree diversity (AIC $=65$ ) (Table 1). These results indicate that soil fungi were affected only the tree species but also soil properties, especially the soil $\mathrm{C}$ and nutrient condition.

Table 1 The effects of environmental variables on soil fungal diversity using one way ANOVA analysis. $P$ value $<0.05$ was bulked.

\begin{tabular}{lcc}
\hline Variables & AIC & $\boldsymbol{P}$ \\
\hline Elevation & 75.234 & 0.178 \\
Aspect & 76.047 & 0.543 \\
Slope & 73.213 & 0.056 \\
\hline
\end{tabular}


Table 1 Continued.

\begin{tabular}{lcc}
\hline Variables & AIC & $\boldsymbol{P}$ \\
\hline DBH & 76.324 & 0.342 \\
Tree height & 75.468 & 0.177 \\
Tree richness & 76.896 & 0.529 \\
Tree diversity & 70.818 & $\mathbf{0 . 0 1 1}$ \\
Litter thickness & 76.956 & 0.562 \\
Soil buck density & 75.432 & 0.475 \\
Soil PH & 77.283 & 0.924 \\
SOC & 76.198 & 0.296 \\
Total_N & 74.046 & 0.072 \\
Total_P & 76.22 & 0.301 \\
Total_K & 75.865 & 0.232 \\
C/N & 72.253 & $\mathbf{0 . 0 2 5}$ \\
C/P & 77.288 & 0.949 \\
N/P & 77.005 & 0.592 \\
Avaiable_P & 77.201 & 0.763 \\
Avaiable_N & 72.666 & $\mathbf{0 . 0 3 2}$ \\
Avaiable_K & 77.264 & 0.867 \\
\hline
\end{tabular}

The effects of dominant tree species on soil fungal communities strongly depend on different taxon and functional levels (Table 2). On the taxon level, soil fungal communities were similar among forest sites $(P=0.141)$, indicating a non-significant effect of dominates tree species on these level (Table 2).

Table 2 The effects of dominant tree species on soil fungal community on taxonomic and functional composition using correlation analysis. $P$ value $<0.05$ were bulked.

\begin{tabular}{lcc}
\hline & \multicolumn{2}{c}{ Tree species } \\
\hline Genetic taxonomy & $\mathrm{R}^{2}$ & $P$ \\
Total Fungi & & \\
Ascomycota & 0.417 & 0.141 \\
Basidimycota & 0.632 & $\mathbf{0 . 0 0 2}$ \\
Functional guilds & 0.355 & 0.260 \\
Symbiotic fungi & & \\
Saprotrophic fungi & 0.376 & 0.311 \\
Pathogenic & 0.602 & $\mathbf{0 . 0 0 8}$ \\
\hline
\end{tabular}

As the predominate group, Ascomycota composition were separately clustered according to dominate tree species (Fig. 4a). Statistical analysis indicated a significant effect of tree species on Ascomycota community and explained $60 \%$ of the variations among trees. In addition, tree characteristic (tree diameter at breast height (DBH), richness, and litter thickness), soil properties (Total $\mathrm{K}$ and $\mathrm{C} / \mathrm{N}$ ) and geographic location (aspect) were significantly correlated with Ascomycota composition variations $(P<0.05)$ (Fig. $4 \mathrm{~b}$ ). The combination of soil $\mathrm{C} / \mathrm{N}$, organic $\mathrm{C}$ and total $\mathrm{K}$ could best explained the Ascomycota community composition (Table 3). Basidiomycota and other fungal phylum were significantly affected by environmental variables (Tree, soil and geographic) rather than dominate tree species. On the functional levels, a significant effect of tree species was 
observed in Saprotrophic fungi composition, where $60 \%$ of the variations in composition could be explained (Fig. 4c). In addition, tree characteristic (Tree DBH, richness, and litter thickness), soil properties (Total $\mathrm{K}$ and $\mathrm{C} / \mathrm{N}$ ) and geographic location (aspect) were significantly correlated with Ascomycota composition variations $(P<0.05)$ (Fig. $4 \mathrm{~d})$. The combination of tree richness, DBH and soil available $P$ could best explained the Saprotrophic fungi community composition (Table 3). Indifferently, Symbiotic and Pathogenic fungi composition was not depending on dominate tree species $(P>0.05$; Table 2$)$.

Table 3 The best model for effects of variables on soil fungal community.

\begin{tabular}{cccccc}
\hline Variables & \multicolumn{2}{c}{ Ascomycota } & Variables & Saprotrophic fungi & \\
\hline & F & $P$ & & F & $P$ \\
Organic C & 2.310 & 0.015 & Tree richness & 2.036 & 0.055 \\
Total_K & 2.477 & 0.005 & Tree DBH & 1.585 & 0.160 \\
C/N & 2.525 & 0.005 & Available_P & 1.903 & 0.075 \\
AIC & 90.11 & & AIC & 93.26 & \\
\hline
\end{tabular}
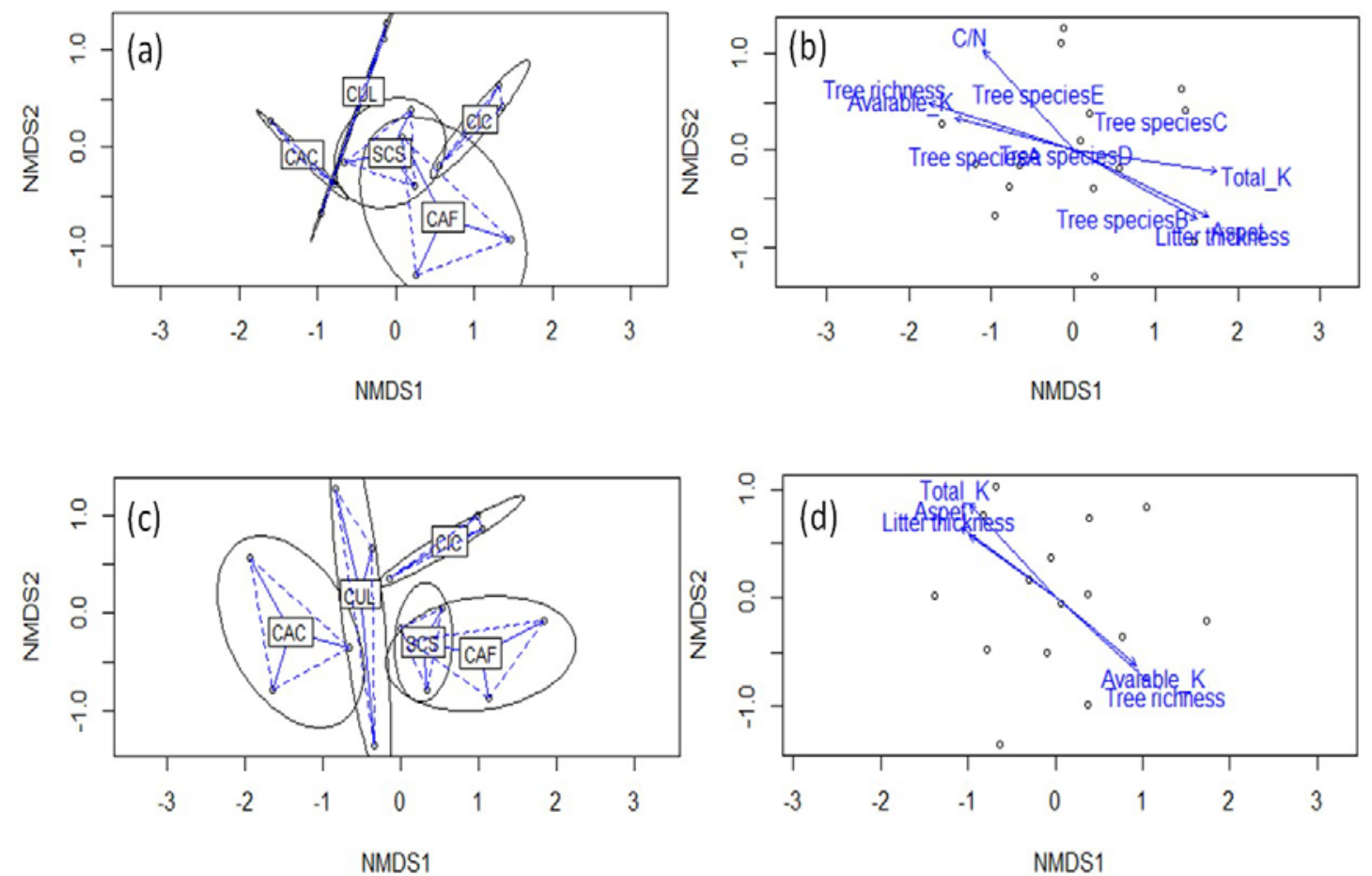

Figure 4 - Nonmetric multi-dimensional scaling plots of the soil Ascomycota and Saprotrophic fungal communities a, c showing the relative differences in community composition. The BrayCurtis distances metric were used to quantify the similarity between phylotype patterns. SCS: Schimasuperba, CAF: Castanopsis fi; CIC: Cinnamomum; CAC: Castanopsis_c (CAC); CUL: Cunninghamia. The significant effects of soil and plant characteristics on soil Ascomycota and Saprotrophic fungal communities b, d based on post-hoc correlations analysis.

\section{Discussion}

\section{The tree species effects on fungi in bulk soil}

Trees may affect ecosystem properties through a multitude of processes, including alteration of the microclimate (temperature and moisture), litter and root exudates input, or direct interactions 
with root-symbiotic and root-associated microorganism (Tedersoo et al. 2016, Hoppe et al. 2016). The importance of individual mechanisms is not well known, but recent results show a strong relationship between soil fungal community structures and soil factors such as $\mathrm{pH}$, texture, organic matter and $\mathrm{C} / \mathrm{N}$ ratio (Bainard et al. 2017). Previous study showed that soil bacterial and fungal biomass content, as well as their ratio was not depending on dominant trees at our study sites but strongly correlated with soil physical and chemical characteristics (Tang et al. 2010, Wang et al. 2013, Song et al. 2015). However, how fungal community composition response to the aboveground plant community differences was still unknown.

Our results demonstrated that the diversity and composition of fungal communities in bulk soil were differing with dominant tree species. It is in agreement with several previous studies, which also observed a significant tree species effect on the general fungal community (Gao et al. 2013, Tedersoo et al. 2016, Holste \& Kobe 2017). However, the significant tree effects in these studies were commonly affected by climate and soil variation caused by large geographic separation. Therefore, our study focuses on tree species variation in regional area, which avoided the disturbances of above environmental factors and shows a much clear tree effects. We found a significant tree-specific effect on dominant taxonomic group (Ascomycota) and functional fungal group (Saprotrophic) (Table 2). In contrast with previous studies focused on rhizosphere fungal communities, where mycorrhizal fungi or other symbiosis fungi are dominate groups, we focus on bulk soil, which was significantly different from rhizosphere in many respects, especially the access and availability of root exudates compounds (Tedersoo et al. 2014, Urbanová et al. 2015, Hamonts et al. 2018). Saprotrophic fungi were affected strongly by tree species, with litter $C$ and nutrients quantities and quality, which have been found different among plant species in this site. However, no tree-special effect was observed on the less abundant fungal groups, such as Symbiotic fungi, which might be explained by the stronger fungal competition interaction with Saprotrophic fungi (Bödeker et al. 2016). Therefore, we proposed that the tree species effect on bulk soil fungi might be strongly affected by microbe interactions.

\section{Indicator Saprotrophic soil fungi in tree species}

Due to the soil fungal community varied among trees, we presumed that each tree has their own unique fungal group. We have identified the dominant Ascomycota, Saprotrophic genus in Castanopsis_c, Castanopsis_fabri, Cinnamomum, and Schima, respectively (Fig. 2b). Most fungi belong to the dominated genus group were yeast, which highly depended on the quality and quantity of substrate they live on (Gupta et al. 2015). At the same time, they were also strong competitor with mycorrhizal fungi. That is to say, tree species could shape these specific groups by litter quality or mycorrhizal fungi types. However, the domination of specific fungal group was not significant in Cunninghamia soil, which presents around 7) unique fungal species with low relative abundances (Fig. 5).

The possible reason could be tree age, since Cunninghamia was much younger than other trees (30 years vs. 80-120 years). Younger tree could have more litter and root exudates inputs to the soil, consequently support more fungal species growth (Haase et al. 2015, Zhang et al. 2017). Moreover, younger tree has not set up their mycorrhizal fungal mycelium web, leading to more fungal co-existing and less microbial competition. Due to the shortage of fungal classification bioinformation, it is still a challenge to figure out the indicator Saprotrophic soil fungi species for different dominate tree species (Tedersoo et al. 2016). The dominant and common distribution patterns for soil fungi depend on tree litter characteristics. However, it is still lack of studies to find out the key chemicals of litter correlate to different fungal groups.

\section{Effects of environmental factors on tree-soil fungi interaction}

Furthermore, our study pointed out that fungal taxonomic and functional groups varied among trees and correlated with different environmental variables. On the taxonomic levels, Ascomycota were not only strongly affected by tree species, but also soil characteristics, such as soil C and N (Table 1). Previous study also found that Ascomycota were correlated with soil pH 
and nutrients (Urbanová et al. 2015). Since minor soil pH variation were observed in our study sites, the changes of Ascomycota species correlated with soil nutrients due to substrate quality. At the functional levels, we found that Saprotrophic fungi strongly correlated with tree diversity tree DBH and soil P. Tree diversity and tree DBG could explain the soil Saprotrophic fungi thought litter inputs, root exudates and also root associate fungi as we discussion above. Soil $\mathrm{P}$ was limitation factors for biotic community in topical and subtropics forest. Especially, soils $\mathrm{P}$ also affects tree mycorrhizal fungi, and then indirectly affect Saprotrophic fungi (Yang et al. 2014, 2016). Besides, we also found slightly impacts of site geographic properties (e.g. elevation, slope and aspects) on some fungal groups. These factors mainly affect the microclimates for fungal habitants, such as soil moisture and temperature. However, we still lack of knowledges in these variables and need further studies on other variables, such as understory cover, and human disturbances.

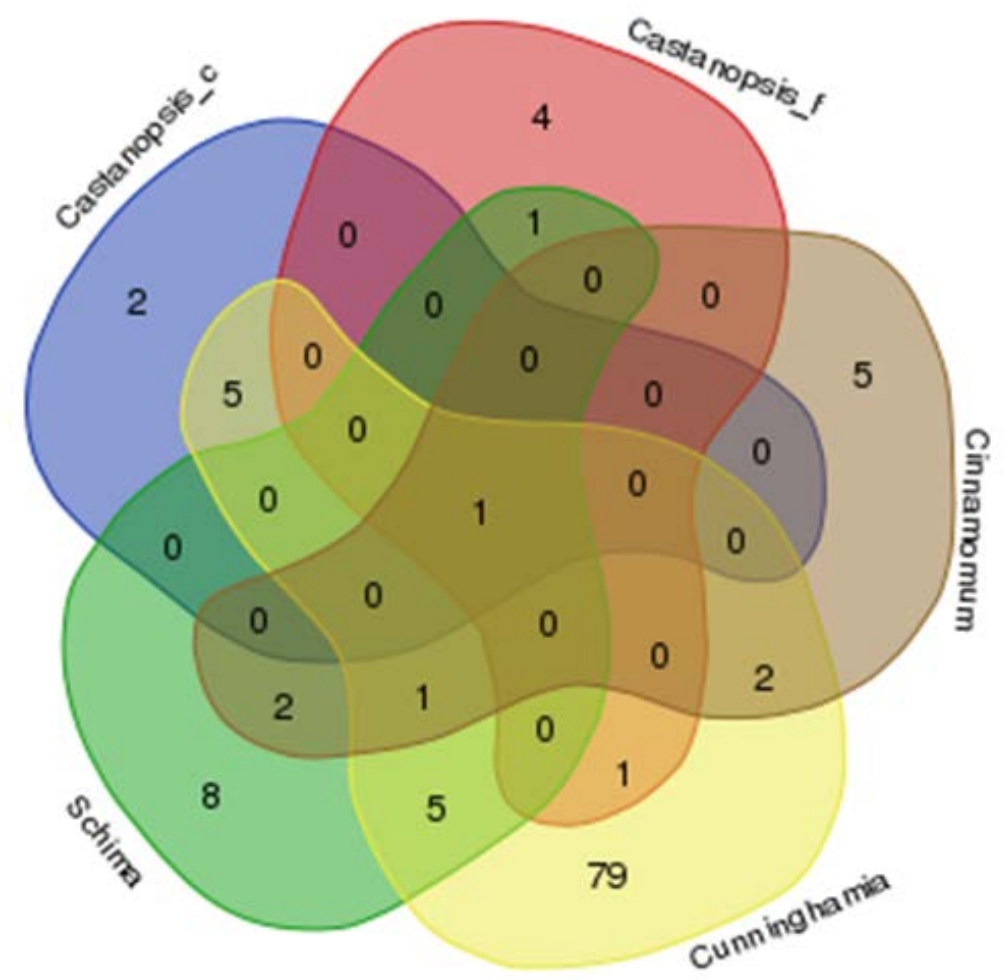

Figure 5 - Venn analysis of the fungal species commonly shared across the five dominate tree species.

\section{Conclusion}

This study examined the effect of dominant tree species on soil fungal at regional scales, which have eliminated the impacts of climate and parental soil characteristics. Our results demonstrate that dominant plant species in subtropical forests not only affect the rhizosphere fungi but also the bulk soil fungi. Among the dominant taxonomic groups, Ascomycota response strongly with tree species changes, together with the changes of tree composition and diameter at breast height. At the functional levels, Saprotrophic fungi changes with dominant tree species, and affected by soil $\mathrm{C}, \mathrm{N}$ and $\mathrm{K}$ concentration. In conclusion, the effects of tree species on bulk soil was content depend, due to different taxonomic and functional groups. This result would be critic for further studies on the interactions between plant and specific fungal groups.

\section{Acknowledgements}

This work was financed by 973 key project of the National Natural Science Foundation of China (2014CB954101). 


\section{References}

Abarenkov K, Henrik Nilsson R, Larsson KH, Alexander IJ et al. 2010 - The UNITE database for molecular identification of fungi-recent updates and future perspectives. New Phytologist 186, 281-285.

Arnold TW. 2010 - Uninformative parameters and model selection using Akaike's Information Criterion. Journal of Wildlife Management 74, 1175-1178.

Bainard LD, Chagnon PL, Cade-Menun BJ, Lamb EG et al. 2017 - Plant communities and soil properties mediate agricultural land use impacts on arbuscular mycorrhizal fungi in the Mixed Prairie ecoregion of the North American Great Plains. Agriculture, Ecosystems and Environment 249, 187-195.

Bardgett RD, van der Putten WH. 2014 - Belowground biodiversity and ecosystem functioning. Nature 515, 505-506.

Bödeker I, Lindahl BD, Olson Å, Clemmensen KE. 2016 - Mycorrhizal and saprotrophic fungal guilds compete for the same organic substrates but affect decomposition differently. Functional Ecology 30, 1967-1978.

Clemmensen KE, Finlay RD, Dahlberg A, Stenlid J et al. 2015 - Carbon sequestration is related to mycorrhizal fungal community shifts during long-term succession in boreal forests. New Phytologist 205, 1525-1536.

Edgar RC, Haas BJ, Clemente JC, Quince C, Knight R. 2011 - UCHIME improves sensitivity and speed of chimera detection. Bioinformatics. 27, 2194-2200.

Gao C, Shi NN, Liu YX, Peay KG et al. 2013 - Host plant genus-level diversity is the best predictor of ectomycorrhizal fungal diversity in a Chinese subtropical forest. Molecular Ecology 22, 3403-3414.

Gupta R, Kumari A, Syal P, Singh Y. 2015 - Molecular and functional diversity of yeast and fungal lipases: their role in biotechnology and cellular physiology. Progress in Lipid Research $57,40-54$.

Haase J, Castagneyrol B, Cornelissen JH, Ghazoul J et al. 2015 - Contrasting effects of tree diversity on young tree growth and resistance to insect herbivores across three biodiversity experiments. Oikos 124, 1674-85.

Nilsson HR, Tedersoo L, Lindahl BD, Kjøller R et al. 2011 - Towards standardization of the description and publication of next-generation sequencing datasets of fungal communities. New Phytologist 191, 314-318.

Hamonts K, Trivedi P, Garg A, Janitz C et al. 2018 - Field study reveals core plant microbiota and relative importance of their drivers. Environmental microbiology. 20, 124-140.

Hiiesalu I, Bahram M, Tedersoo L. 2017 - Plant species richness and productivity determine the diversity of soil fungal guilds in temperate coniferous forest and bog habitats. Molecular ecology 26, 4846-4858.

Holste EK, Kobe RK. 2017 - Tree species and soil nutrients drive tropical reforestation more than associations with mycorrhizal fungi. Plant and soil 410, 283-297.

Hoppe B, Purahong W, Wubet T, Kahl T et al. 2016 - Linking molecular deadwood-inhabiting fungal diversity and community dynamics to ecosystem functions and processes in Central European forests. Fungal Diversity 77, 367-379.

Kõljalg U, Nilsson RH, Abarenkov K, Tedersoo L et al. 2013 - Towards a unified paradigm for sequence-based identification of fungi. Molecular Ecology 22, 5271-5277.

Lindahl BD, De Boer W, Finlay RD. 2010 - Disruption of root carbon transport into forest humus stimulates fungal opportunists at the expense of mycorrhizal fungi. The ISME journal 4, 872881.

Nguyen NH, Song Z, Bates ST, Branco S et al. 2016 - FUNGuild: an open annotation tool for parsing fungal community datasets by ecological guild. Fungal Ecology 20, 241-248. 
Ortega-Martínez P, Águeda B, Fernández-Toirán LM, Martínez-Peña F. 2011 - Tree age influences on the development of edible ectomycorrhizal fungi sporocarps in Pinus sylvestris stands. Mycorrhiza 21, 65-70.

Pineda A, Soler R, Pozo MJ, Rasmann S et al. 2015 - Above-belowground interactions involving plants, microbes and insects. Frontiers in plant science 6, 318-319.

Pellissier L, Niculita-Hirzel H, Dubuis A, Pagni M et al. 2014 - Soil fungal communities of grasslands are environmentally structured at a regional scale in the Alps. Molecular ecology. 23, 4274-4290.

Purahong W, Wubet T, Lentendu G, Schloter M et al. 2016 - Life in leaf litter: novel insights into community dynamics of bacteria and fungi during litter decomposition. Molecular Ecology 25, 4059-74.

Quail MA, Kozarewa I, Smith F, Scally A et al. 2008 - A large genome center's improvements to the Illumina sequencing system. Nature Methods 5, 1005-1010.

Reeder J, Knight R. 2010 - Rapidly denoising pyrosequencing amplicon reads by exploiting rankabundance distributions. Nature Methods 7, 668-669.

Schimann H, Bach C, Lengelle J, Louisanna E et al. 2017 - Diversity and structure of fungal communities in neotropical rainforest soils: the effect of host recurrence. Microbial Ecology 73, 310-320.

Schmidt PA, Bálint M, Greshake B, Bandow C et al. 2013 - Illumina metabarcoding of a soil fungal community. Soil Biology and Biochemistry 65, 128-132.

Shi LL, Mortimer PE, Slik JF, Zou XM et al. 2014 - Variation in forest soil fungal diversity along a latitudinal gradient. Fungal Diversity 64, 305-315.

Song P, Ren H, Jia Q, Guo J et al. 2015 - Effects of historical logging on soil microbial communities in a subtropical forest in southern China. Plant and Soil 397, 115-126.

Sterkenburg E, Bahr A, Brandström Durling M, Clemmensen KE, Lindahl BD. 2015 - Changes in fungal communities along a boreal forest soil fertility gradient. New Phytologist. 207, 114558.

Tang CQ, Li YH, Zhang ZY. 2010 - Species diversity patterns in natural secondary plant communities and man-made forests in a subtropical mountainous karst area, Yunnan, SW China. Mountain Research and Development 30, 244-251.

Tedersoo L, Nilsson RH, Abarenkov K, Jairus T et al. 2010 - 454 Pyrosequencing and Sanger sequencing of tropical mycorrhizal fungi provide similar results but reveal substantial methodological biases. New Phytologist 188, 291-301.

Tedersoo L, Bahram M, Põlme S, Kõljalg U et al. 2014 - Global diversity and geography of soil fungi. Science 346, 1095-1102.

Tedersoo L, Bahram M, Cajthaml T, Põlme S et al. 2016 - Tree diversity and species identity effects on soil fungi, protists and animals are context dependent. The ISME Journal 10, 346347.

Urbanová M, Šnajdr J, Baldrian P. 2015 - Composition of fungal and bacterial communities in forest litter and soil is largely determined by dominant trees. Soil Biology and Biochemistry 84, 53-64.

Wagg C, Bender SF, Widmer F, van der Heijden MG. 2014 - Soil biodiversity and soil community composition determine ecosystem multifunctionality. Proceedings of the National Academy of Sciences 111, 5266-5270.

Wang H, Liu S, Wang J, Shi Z et al. 2013 - Effects of tree species mixture on soil organic carbon stocks and greenhouse gas fluxes in subtropical plantations in China. Forest Ecology and Management 300, 4-13.

Wardle DA, Bardgett RD, Klironomos JN, Setälä H et al. 2004 - Ecological linkages between aboveground and belowground biota. Science 304, 1629-1633.

Větrovský T, Baldrian P. 2013 - Analysis of soil fungal communities by amplicon pyrosequencing: current approaches to data analysis and the introduction of the pipeline SEED. Biology and Fertility of Soils, 49, 1027-1037. 
Yang G, Liu N, Lu W, Wang S et al. 2014 - The interaction between arbuscular mycorrhizal fungi and soil phosphorus availability influences plant community productivity and ecosystem stability. Journal of Ecology 102, 1072-82.

Yang G, Yang X, Zhang W, Wei Y et al. 2016 - Arbuscular mycorrhizal fungi affect plant community structure under various nutrient conditions and stabilize the community productivity. Oikos 125, 576-85.

Yang YS, Chen GS, Guo JF, Xie JS, Wang XG. 2007 - Soil respiration and carbon balance in a subtropical native forest and two managed plantations. Plant Ecology 193, 71-84.

Zhang C, Liu G, Song Z, Qu D et al. 2017 - Natural succession on abandoned cropland effectively decreases the soil erodibility and improves the fungal diversity. Ecological Applications 27, 2142-2154. 